DOI https://doi.org/10.18551/rjoas.2017-10.15

\title{
INNOVATIVE SYSTEM MANAGEMENT MECHANISM IN THE EARLY STAGES OF INNOVATION
}

\author{
Novikov S.V. ${ }^{*}$, Gavrilova I.S., Candidates of Economic Sciences \\ Moscow Aviation Institute (National Research University), Moscow, Russia \\ *E-mail: ncsrm@mail.ru
}

\begin{abstract}
One of the main management elements in the development and implementation of innovation is the various organizational and economic interactions aimed at acquiring and transferring knowledge and technology between developing, productive, scientific and educational organizations. The quality, intensity, and early timing of the developing enterprises entering into the interaction network determine the achievement of "breakthrough" improvements, the long-term efficiency and desired performance of the final high-tech products. The model of innovation management change process in the early stages of the product development cycle is based on systematic and coordination-oriented approaches using Robust Portfolio Modeling. The results of the study are as follows: the main stages of project evaluation and selection, management procedures for developing the process of selecting the potential scientific and innovative networks, the tools for their implementation, and the system of interrelation between the major stages of the innovation development cycle. The field of application of the research results is management and planning systems of enterprises working in the early stages of the innovation cycle, where originators and sources of innovation may be the users themselves.
\end{abstract}

\section{KEY WORDS}

Innovation, stages, life cycle; management processes, systematic approach, Robust Portfolio Modeling, scientific and innovative networks.

Market demands to reduce the development cycle time and increased competition in the market for high technology producers have led to the need of further change of organization and management in the design processes of the life-cycle stages of innovation. The increasing complexity of innovation systems makes traditional management processes inoperative for innovation, leads to delays in entry into the market and, as a result, unexpected expenditures.

The main setbacks of current management processes can be identified as:

- Low percentage of conceptual management decisions in the early stages of the life cycle of innovative products development;

- Belated involvement of external developers and suppliers to the life-cycle stages of innovative product development;

- Low contribution of external sources to research and technology; only the local specification for customers' requests, etc.

The development of networking among developers, manufacturers, suppliers, higher educational institutions, etc. takes place in isolation from the selection of priority innovative programmes and projects. These issues are usually dealt with later, in the further stages of the life cycle of an innovation project or in order to take part in competitive procedures [1]. Often the need to take into account the many horizontal and vertical connections - both within the innovation system and in the interaction with the external environment - increases the time spent on the project implementation and, as a result, reduces its efficiency in operation.

The results of the development assessment and acceleration of the life-cycle processes for the creation of the innovation; the expansion of external sources for scientific and applied research, as well as the development of technology in the manufacturing of 
products, have shown that the solution to the current situation is to apply the systematic approach to a number of key elements, such as:

- Identification of priorities in the evaluation of innovative projects, taking into account the range of possible prospects, alternative ideas;

- To reduce the turnaround time for new developing innovative technologies from the point of view of the competitiveness of the process;

- Establishment and development of networking, as well as restructuring of the existing networks, starting from the early stages of innovative projects and programmes;

- Expansion of management tools to attract external sources aimed at building various networks, including technology platforms;

- Restructuring of the product development process as an activity from the product vision that originates from the customer's needs, etc.

This requires changes and improvements in the traditional methodology for the selection of programmes and projects based on investment assessment, as well as the search for new strategic innovative solutions in the context of uncertainty and diversity of choice.

When choosing a system of criteria for evaluating innovative projects in life cycle stages, the requirements for finding attractive projects and evaluating them in a context of incomplete information are mandatory. The difficulties of selection also arise in determining the benefits of one project before another, because in a decision-making process, where a combination of qualitative and quantitative characteristics and the possibility of using a costsharing effect and unique characteristics of an innovative project are taken into account, when it is implemented with the existing enterprise projects.

In the proposed study, the selection of design solutions in the context of limited resources and perhaps incomplete information on the relative importance of the evaluation criteria and the functionality of the projects is given by the Robust Portfolio Simulation approach [2].

The proposed model for management changes in innovation in the development of high-tech products, taking into account the assessment and selection of innovative ideas, includes a system of criteria for "innovative attractiveness" of projects and criteria for the selection of potential associate contractors in scientific and innovation networks. This allows integrating the processes of identifying the priorities of innovative ideas and building the cooperation networks, starting from the early stages of innovative programming in project selection.

The intensity and quality of such interactions are getting more significant in assessing the level of innovation systems, which are currently presented as scientific and cooperating networks based on interaction within a broader system that consists of external developers, suppliers, distributors, customers, etc.

The scientific and cooperating network is a combination of scientific, educational and industrial organizations and companies associated with strong partnerships and a unified by a common specific goal.

In scientific networks, the focus is on maintaining and implementing a complete innovation cycle, from generating new knowledge to translating it into a specific product or technology. They are implemented within the project chains that are developed within the network to maximize the initial stages of the innovation cycle (generic, marginalized, precompetitive research) and are progressing through the stages life cycle of innovative products and beyond. Such networking interactions are particularly relevant if it is a major innovation project of representatives of scientific institutions, industry, institutions of higher education, invested from different sources, and ensuring vast involvement. The use of the portfolio modeling method does not only reveal promising innovative fields of research, but also a possible network architecture for the management of the innovation system in the early stages. Project evaluation in terms of cooperation with scientific and industrial enterprises will also be important for attracting investment in the project, as this interaction points to future demand by industry and consumers. Cooperation also shows that there is a necessary interest in scientific organizations with the status and the expertise to successfully 
implement the objectives of an innovative project. Thus, rather than separating the processes of selection of innovative ideas, programmes, projects and networking in the management and planning of innovative development, it is advisable to unite them over time; this will make it possible to focus on ideas around which you can build a new network architecture [3].

Taking into account the above characteristics of the management procedural schemes for the evaluation and selection of innovative projects in enterprises, it is proposed to build the model for implementing management changes in innovation activity in high-tech product development with consideration of network management architecture for the innovation cycle stages, which includes:

- Pre-Selection of projects for consideration by thematic priorities;

- Consolidated (enlarged) evaluation of selected projects by the criteria of innovation;

- Assessment of networking interaction opportunities in project selection;

- Investment and project risk assessment;

- Final selection of the project (projects) of the innovation.

The main criteria for selecting priority innovative ideas may be novelty, feasibility, consumer value. The criteria system also includes the potential cost and cost of the long-term idea for the enterprise; a requirement for an enterprise's capacity to implement the idea; the difference between the ideas and the existing developments; the ability to execute a plan in the context of undefined and critical project parties on time and in a cost-effective manner; etc. Further selection of priority and value, pre-selected innovative ideas includes an assessment of the set of the criteria for evaluating innovative ideas and networking criteria that have already been chosen.

To assess the value of network cooperation, a system of qualitative and quantitative criteria has been used that takes into account the competencies of the development researchers: level of the specialist in a thematic field; public image of the researcher's business; the level of competence of the author's idea, the experience of participating in networking; the extent of interest in participating in the project, etc.

The set of management procedures for the selection of scientific and cooperation networks in the shaping of the project includes the following management decision blocks:

- Consistent multi-criteria consumer selection of potential partners for shaping a scientific and cooperation networks and efficient information exchange at the design and implementation stages of innovative products/technologies;

- Selection of ways and principles of information interaction in the science and cooperation network to maintain and enhance the competitiveness of the enterprise;

- Testing of management procedures in the approval of the list of innovative ideas, taking into account the scientific and cooperation networks as projects;

- Development of a portfolio of orders for innovative enterprise development.

It has been accepted in the study that scientific and cooperation networks (technology platforms, clusters, strategic alliances, etc.) are a communication tool aimed at intensifying efforts to build prospective innovative technologies, new products (services), as well as at attracting additional resources for research and development through the participation of all parties concerned (business, science, state, civil society).

Conclusion. The development of organization and management in the innovation system, starting from the early stages of the innovation cycle, as well as the prospects for their development, offer new ideas for improving innovation processes. The diversity of economic models of management in the design and development of this type of product highlights the development of the network management architecture. Design processes are presented as a network based on interaction within a broader system consisting of competitors, suppliers, distributors, consumers, and so forth.

The proposed adaptation model of management change implementation in innovation includes a cumulative assessment of innovative ideas and assessment of potential associate contractors in the science and innovation network from the early stages of the life cycle. Communication is provided in the network of collaborators of major participants in the design and implementation of an innovative project, a programme for all stages of the life cycle. 
The introduction of a model for management changes in innovation in Russian enterprises will make it possible to strengthen decision-making on coordination of the interaction of a significant number of parties involved in the process, particularly in the practical application of emerging new products and technologies, to minimize time frames, costs of project design and implementation, taking into account their long-term efficiency and desired performance.

Integrational formations are particularly important in moving to the market, providing financial resources, acquiring new technologies, sharing risks and achieving other opportunities and resources beyond the capabilities of separate enterprises.

\section{REFERENCES}

1. Gavrilova I.S., Novikov S.V. Contract System in state procurements: theory and practice. Moscow, 2017.

2. Zakharova L. F., Novikov S.V. Management of competitive selection of high-tech science and technology projects. Moscow, 2016.

3. Novikov S.V. The national economy is a large-scale organizational socio-economic system. Vestnik of University. 2014. No.6. pp. 125-132.

4. Tikhonov A.I., Novikov S.V. Institutional aspects of state personnel policy in Russia. Management and business administration. 2017. No.2. Pp. 25-32.

5. Korzhueva L.M. Development of regulatory frameworks and preconditions for the formation of an innovative educational complex. Collection: The post-crisis outlines of innovative processes. Material of the Tenth Drucker Readings. 2010. pp. 237-241.

6. Novikov S.V. Innovation policy of an institution of higher education in the field of publicprivate partnership. Dvigatel'. 2011 No. 6. pp. 46-47.

7. Gavrilova I.S., Kanaschenkov A.A., Meshankov D.V. Business philosophy of innovative companies. Science of XXI century - a glance into the future, I international scientific and practical conference. 2016. pp. 17-21.

8. Kanaschenkov A.A., Gavrilova I.S., Meshankov D.V. Business integrity and the culture of modern innovation companies. Science of XXI century - a glance into the future, I international scientific and practical conference. Pp. 23-26.

9. Novikov S.V. Innovative methods for work process design in a high technology enterprise Russian Journal of Agricultural and Socio-Economic Sciences. 2017. Vol. 68. №8. pp. 114-117.

10. Mindlin, Y.B. Innovative territorial clusters//International Journal of Economics and Financial Issues, 2016, 6(S8), pp. 251-256

11. Zolotukhina E.B., Bakharev V.V., Kapustina I.V., Novikov S.V., Lygina N.I. Sales management of the chain retail establishments. International Journal of Applied Business and Economic Research. 2017. Vol. 15. №11. pp. 19-27. 